\title{
Oxidative Burst of Neonatal and Adult Peripheral Blood Phagocytes Confronting Escherichia coli and Candida albicans
}

\author{
FLOREDANA-LAURA ȘULAR ${ }^{1,2^{*} \#}$, MIHAELA IANCU ${ }^{3, \#, ~ M A N U E L A ~ C U C E R E A ~}{ }^{1,4}$, \\ ELENA MOLDOVAN ${ }^{1,4}$, MARIA LIVIA OGNEAN ${ }^{5}$, MINODORA DOBREANU ${ }^{1,2}$
}

${ }^{1}$ University of Medicine and Pharmacy of Târgu-Mureş, Romania

${ }^{2}$ Central Laboratory, Emergency Clinical County Hospital of Târgu Mureş, Romania

${ }^{3}$ Department of Medical Informatics and Biostatistics, University of Medicine and Pharmacy

Iuliu Hatieganu Cluj-Napoca, Romania

${ }^{4}$ Regional Center of Neonatal Intensive Care Unit UGON of Târgu Mureș, Romania

${ }^{5}$ Clinical County Emergency Hospital, Sibiu, Romania

\#Contributed equally to this work.

\begin{abstract}
The functional immaturities of the cells responsible for the innate defense in neonates have often been considered a significant risk factor for perinatal infections. The ability of the neutrophils and monocytes to generate reactive oxygen species (ROS) is mandatory for efficient killing of bacteria and fungi. This study aimed to assess the production of reactive oxygen species (ROS), as well as the differences in leucocyte populations in healthy preterm and term neonates, using healthy adults as controls. Burst activation of peripheral blood phagocytes (PBPs) was quantified by using a flow cytometry method that implied incubation of peripheral whole blood phagocytes with various stimuli that included an opsonized Escherichia coli and a non-opsonized Candida albicans yeast suspension. We observed a smaller population of activated granulocytes after exposure to E. coli in premature neonates than in control adults $(41.19 \pm 20.63 \%$ vs. $58.32 \pm 33.46 \%, \mathrm{p}=0.058)$. Monocyte burst activation triggered by $E$. coli, although lower in preterm than in control adults was not significantly different $(38.97 \pm 20.73 \%$ vs. $46.82 \pm 21.05 \%, \mathrm{p}>0.05)$. Incubation with non-opsonized $C$. albicans led to a similar low granulocyte and monocyte activation in all studied groups, reaching a statistically significant difference only between term neonates and adults. The study shows a deficit of the premature neonate granulocyte to generate ROS when exposed to opsonized E. coli. The preterm and term, as well as the adult PBPs presented an almost similar low oxidative burst when exposed to C. albicans, in spite of the evoked functional immaturity of the preterm neonate phagocytes.
\end{abstract}

Keywords Reactive oxygen species, flow cytometry, Escherichia coli, Candida albicans.

To cite this article: ȘULAR F-L, IANCU M, CUCEREA M, MOLDOVAN E, OGNEAN ML, DOBREANU M. Oxidative Burst of Neonatal and Adult Peripheral Blood Phagocytes Confronting Escherichia coli and Candida albicans. Rom Biotechnol Lett. 2020; 25(2): 1340-1347. DOI: 10.25083/rbl/25.2/1340.1347

*Corresponding author: FLOREDANA-LAURA ȘULAR, University of Medicine and Pharmacy of Târgu-Mureş, Department of Laboratory medicine, Gh. Marinescu street, No. 50, Târgu-Mureş Romania, E-mail: floredana.sular@gmail.com 


\section{Introduction}

The developmental immaturities of the cells responsible for the innate defense in neonates have often been considered a significant risk factor for perinatal infections. The innate immune impairment of the neonate is characterized by a small storage pool of neutrophils at birth, reduction in serum complement activity (GRUMACH, 2014), low ability to produce antibodies against bacterial antigens and an increased percentage of "naïve" T lymphocytes. Although monocytes seem to function adequately in neonates, they have limited chemotactic responses (SCHELONKA, 1998).

Candida species have been described lately as increasingly important pathogens in premature neonates, especially the among very low birth weight infants (VLWB). Invasive Candida infections are known as the third most common cause of late-onset sepsis in the preterm immunocompromised populations, its incidence ranging from $7 \%$ to $12 \%$ (BENJAMIN, 2006).

The neutrophil, accompanied by the monocyte, are key effector cells in bacterial and fungal infections. The ability of the neutrophils and monocytes to generate ROS is mandatory for efficient killing of infectious bacteria and fungi (C. FRADIN, 2005). Consequently, the respiratory burst alterations may be a reflection of the neonates' increased susceptibility to infections and their detection could be an early diagnostic tool of infection. Some studies have also shown the decreased ability of the preterm neutrophil to generate an oxidative burst in response to bacteria (KÄLLMAN, 1998).

The opsonization status pays also an important role in granulocyte activation in the presence of the $C$. albicans yeast, phagocytosis being quite low in the absence of opsonins and enhanced greatly when they were introduced in the reaction medium (WELLINGTON, 2003; GAZENDAM, 2014). The PBPs of the neonates may have a different response to Candida than to bacterial stimuli due to the different structure of the fungal wall and larger size than bacteria.

The objectives of the present study were: i) to identify the impact immaturity in preterm and term neonates has on the ability of PBPs to generate ROS in the presence of various stimuli when compared to healthy adults and ii) to establish how active neonatal PBPs are in producing ROS when exposed to a bacterial opsonized Escherichia coli stimulus in comparison to non-opsonized $C$. albicans yeast. The opsonins were deliberately omitted from our study so that the innate function of PBPs could be evaluated at its basic level. We hypothesized that production of ROS would be more decreased in neonatal PBPs than in adults when exposed to both $E$. coli and $C$. albicans, and that this decrease would be more obvious in preterm neonates. We considered that this behavior could account for the high susceptibility of the preterm neonates to develop invasive infections.

\section{Material and Method}

Study population and blood samples. The sampled population included 30 preterm neonates (25-34 weeks gestational age) and 18 term neonates (37-41 weeks gestational age) admitted to the Neonatology Clinic and the Regional Center of Neonatal Intensive Care Unit UGON of the Emergency Clinical County Hospital of Târgu Mureș, Romania, as well as a control group of healthy volunteer adults $(n=26)$. They were selected from the laboratory staff and chosen by the absence of clinical signs of infection. The studied neonates were recruited between November 2014 - September 2015. Only neonates that met the inclusion criteria that ruled out any sign of inflammation or sepsis during their first 7 days of life were admitted to the present study ( $\mathrm{C}$ reactive protein (CRP) levels lower than $10 \mathrm{mg} / \mathrm{L}$ and corrected $\mathrm{WBC}$ count $>5000 / \mu \mathrm{L}$ and $<30000 / \mu \mathrm{L}$ in neonates, $\mathrm{I} / \mathrm{T}$ (immature nucleated cells/total white blood cells) $\leq 1.16$ for the first 24 hours of life and $\mathrm{I} / \mathrm{T} \leq 1.12$ within 60 hours of life and a WBC count $<11000 / \mu \mathrm{L}$ in adults) (CHIRICO, 2011; CHIESA, 2004). Two term and one preterm neonate were excluded from the study due to difficult sampling that led to coagulation.

Blood samples for CBC count, lymphocyte count and peripheral blood smears were collected by heel pricks in $\mathrm{K}_{3}$ EDTA tubes, while the blood for burst oxidation assessment and CPR quantification was collected by peripheral venipunctures.

The study was conducted according to the World Medical Association Declaration of Helsinky and was approved by the Ethics Committee of the Emergency Clinical County Hospital of Târgu Mures, No. 19204/29th of September 2014. Informed consent was given by the mothers of neonates and the volunteer adults.

Blood cell counts and CRP assessment. The complete blood count (CBC) included a nucleated cell count (Sysmex XT-4000i $i^{\mathrm{TM}}$, Kobe, Japan) platelet count and a peripheral blood smear 100-cell differential count. The nucleated cell count represents the total WBC count, corrected for the presence of nucleated red blood cells. The I/T ratio was calculated for all neonates as the total percentage of immature neutrophils divided by the total percentage of neutrophils in the peripheral blood.

The serum CRP levels were assessed by using an automated latex immunoassay (Architect Plus c4000, Abbott, Chicago, Illinois, USA).

Lymphocyte subsets quantification. Fifty microliters of well mixed reversed pipetted whole blood and 20 microliters of a fluorochrome-conjugated monoclonal antibody (CD3/CD19/CD45, CD3/CD16+CD56/CD45, CD4/CD8/CD3) (Becton Dickinson Biosciences, San Jose, $\mathrm{CA}$, USA) were well mixed in a $5 \mathrm{~mL}$ round bottom BD tube and incubated for 15 minutes on an ice bath in the dark. Two milliliters of a lysing solution (FACS Lysing Solution, BD) was added, followed by gentle vortexing and 
a 10 minute incubation period in the dark on a covered ice bath. Samples were then centrifuged at $300 \mathrm{x} g$ for 5 minutes and the supernatant was removed. Two milliliters of BD Cell Wash solution was added and samples were centrifuged at $200 \mathrm{x} g$ for another 5 minutes, followed by removal of the supernatant. Upon the remaining cells, $250 \mu \mathrm{L}$ of $1 \%$ paraformaldehyde solution was added and mixed thoroughly. Samples were stored at $2^{\circ}-8^{\circ} \mathrm{C}$ and analyzed within 4 hours. Data acquisition and analysis were performed with a FACSCalibur four colour dual laser flow cytometer and CellQuest software (BD, San Jose, CA, USA). The gating strategy was CD45 versus side scatter.

Oxidative burst assay. Whole venous blood specimens collected by venipuncture in BD sodium heparin tubes were used for quantification of oxidative burst activity of neutrophils and monocytes. All samples were tested within 1 hour after collection, being kept meanwhile on a covered ice bath.

The production of ROS was quantified by an in vitro diagnostic flow cytometry method (Phagoburst ${ }^{T M}$, Glycotope Biotechnology). The kit uses an unlabeled opsonized Escherichia coli suspension as particulate stimulus (approximatively 1-2 x $10^{9}$ bacteria/mL), the chemotactic peptide $\mathrm{N}$-formyl-methionyl-leucyl-phenylalanine (fMLP) as low physiological stimulus and the protein kinase $\mathrm{C}$ ligand phorbol 12-myristate 13-acetate (PMA) as high stimulus. In order to assess the production of ROS by PBPs that could be triggered by an invasive fungal infection in the absence of opsonins, we introduced for testing an additional fungal stimulus in the form of a Candida albicans yeast suspension. Candida albicans ATCC 10321 provided by the Bacteriology Department of our laboratory was cultured aerobically on Sabouraud chloramphenicol agar for 18 hours at $35^{\circ} \mathrm{C}$. An inoculum of 0.5 optical density $C$. albicans suspension (approximate cell concentration of $1-5 \times 10^{6}$ colony forming units $/ \mathrm{mL}$ ) was prepared for each testing round by Using Vitek2 Densichek densitometer (Biomerieux, France). No opsonins were added to the yeast suspension. One hundred microliters of whole blood, previously kept on an covered ice bath, no longer than 1 hour after blood collection, were incubated with $20 \mu \mathrm{L}$ of each of the above mentioned stimuli for 10 minutes at $37^{\circ} \mathrm{C}$. Production of the reactive oxidants during oxidative burst was monitored by the addition and oxidation of $20 \mu \mathrm{L}$ of dihydrorhodamine 123 (DHR123) which served as an oxidative fluorogenic substrate. Burst oxidation was stopped by adding $2 \mathrm{~mL}$ of lysing solution which removed the erythrocytes and led to a partial fixation of the leucocytes. After centrifugation and one washing step, $200 \mu \mathrm{L}$ DNA staining solution was added to exclude aggregation artifacts caused by bacteria, fungi or cells. The DNA staining required 10 minutes incubation at $0^{\circ} \mathrm{C}$, protected from light. Samples were thus ready for the FACS analysis that was performed within 30 minutes following DNA staining. Cells were analyzed by flow cytometry using a $488 \mathrm{~nm}$ argon-ion excitation laser. According to the recommendations of the producer, during data acquisition a "live gate" was set in the red fluorescence histogram on the events that had at least the same DNA content as a human diploid cell with the purpose of precluding from analysis bacteria or fungi aggregates that had the same scatter light properties as the leukocytes. An average number of 15000 leukocytes per sample were collected. The percentage of cells that produced ROS (recruitment) was quantified. The relevant leukocyte cluster was gated in the software program in the scatter diagram (linear FSC vs linear SSC) and its rhodamine 123 green fluorescence was collected in the FL1 channel (standard FITC filter set) and analyzed. A control sample of a healthy adult stimulated with saline was used as a negative control to set a marker for fluorescence (FL1) so that less than $3 \%$ of the events were positive. The percentage of activated cells in the test samples was then set by counting the number of events above this threshold. The final percentage of activated cells was obtained by subtracting for each sample the negative control activated cells from the percentage of activated cells stimulated by various stimuli.

Statistical analysis. The percentage of activated cells was considered as a continuous variable and was expressed by descriptive statistics as mean \pm standard deviation (SD) or median and interquartile range [Q1, Q3] where Q1 represented the first quartile (25th percentile) and Q3 the third quartile ( $75^{\text {th }}$ percentile). The assumption of normal distribution of the studied variables was verified by multiple methods such as Shapiro-Wilk test, Q-Q plot or $95 \%$ confidence interval for univariate skewness and kurtosis estimates.

In order to compare the absolute count of white blood cells (WBC), neutrophils, monocytes and lymphocytes and the percentage of lymphocyte subclasses (total $\mathrm{T}$, $\mathrm{T}$ helper, T cytotoxic, B and NK lymphocytes) between the studied groups, we used the ANOVA method or Welch test considered as an appropriate approach for heterogeneity of variance in our data.

Because we were interested in comparing the percentage distribution of the activated cells triggered by different intra group stimuli (adults), the Student- $t$ test for dependent samples was performed.

In order to compare the percentage of activated cells caused by different stimuli inter groups (premature neonates vs. adults and premature vs. term neonates), we used the parametric Student- $t$ test for independent samples or the nonparametric Mann-Whitney test.

Because of multiple released comparisons, we reported adjusted $p$ values for appropriate statistical tests in order to maintain the family error rate to the alpha value of 0.05 .

For all two-sided statistical tests for group comparisons, the statistical significance was achieved if adjusted $p$ values $\leq 0.05$.

The statistical analysis was performed with the advanced software environment for statistical computing and graphics, R version 3.2.4 (R Foundation for Statistical Computing, Vienna, Austria), STATISTICA (StatSoft, USA, version 6) and MedCalc version 17. 


\section{Results}

Clinical characteristics of the studied neonates (see Table 1). The studied preterm and term neonatal groups presented no differences regarding gender and maternal age $(p>0.05)$. Birth weight was significantly lower in preterm neonates $(p<0.0001)$ and preeclampsia was a condition that affected only $13.33 \%$ of the mothers of the studied preterm neonates. The caesarean way of delivery was more often encountered in the case of preterm neonates, more than half of them $(60 \%)$ being delivered this way compared to term neonates $(20 \%)(p=0.0167)$. Tocolytic medication was administered to two mothers of the preterm and one of the term neonates, while dexamethasone prophylaxis was used for half of the mothers of the preterm neonates. Chorioamnionitis and systemic infection were not present in any of the mothers of either neonatal group. Prophylactic antibiotic therapy was administered for ruptured membranes to $30 \%$ of the mothers of the preterm neonates.

Table 1. Clinical characteristics of the studied neonates

\begin{tabular}{|c|c|c|c|}
\hline & Preterm & Term & $p$ \\
\hline Number & $\mathrm{n}=30$ & $\mathrm{n}=18$ & \\
\hline $\begin{array}{l}\text { Maternal age } \\
(\text { mean } \pm \mathrm{SD}, \text { years })\end{array}$ & $26.21 \pm 1.36$ & $26.88 \pm 1.8$ & $0.7677 *$ \\
\hline $\begin{array}{l}\text { Delivery } \\
(\text { Vaginal/Caesarean })(\%)\end{array}$ & $12 / 18$ & $14 / 4$ & $0.0167 * *$ \\
\hline Male/female gender (\%) & $10 / 16$ & $11 / 7$ & $0.2199 * *$ \\
\hline $\begin{array}{l}\text { Gestational age } \\
(\text { mean } \pm \mathrm{SD}, \text { weeks })\end{array}$ & $30.15 \pm 2.7$ & $38.85 \pm 1.14$ & $\begin{array}{c}\mathrm{P}<0.0001 \\
*\end{array}$ \\
\hline $\begin{array}{l}\text { Birth weight } \\
(\text { mean } \pm \text { SD , grams })\end{array}$ & $1388 \pm 443.5$ & $3239 \pm 440.9$ & $\begin{array}{c}\mathrm{P}<0.0001 \\
*\end{array}$ \\
\hline \multicolumn{4}{|l|}{ Maternal conditions } \\
\hline Preeclampsia $-\mathrm{n}(\%)$ & $4(13.33 \%)$ & 0 & ND \\
\hline Chorioamnionitis $-\mathrm{n}(\%)$ & 0 & 0 & ND \\
\hline Systemic infection $-\mathrm{n}(\%)$ & 0 & 0 & ND \\
\hline Diabetes $-\mathrm{n}(\%)$ & 0 & 0 & ND \\
\hline \multicolumn{4}{|l|}{ Maternal medications } \\
\hline Corticoid prophilaxis (DXM) $-\mathrm{n}(\%)$ & $15(50 \%)$ & 0 & ND \\
\hline Tocolytics $-\mathrm{n}(\%)$ & $2(7.69 \%)$ & $1(5.55 \%)$ & 1.000 \\
\hline Antibiotics $-\mathrm{n}(\%)$ & $9(30 \%)$ & 0 & ND \\
\hline
\end{tabular}

*Student $-t$ test for independent samples; **Fisher's Exact test; $\mathrm{SD}=$ standard deviation; $\mathrm{ND}=$ not determined; $\mathrm{DXM}=$ dexamethasone

WBC and lymphocyte subclasses in neonates and adults. We identified a significant difference between the absolute count of WBC in preterm and term neonates when compared to adults ( $p=0.029$, and $p=0.003$ respectively), the mean of corrected absolute count of WBC value being greater in the term neonate group than in preterm neonates and adults (Table 2). We found also a significant difference between the mean of neutrophil absolute count in term neonates and adults $(p=0.015)$, but there was no difference identified between preterm neonates and adults. The mean of neutrophil count was greater in the term neonate group than in adults (Table 2).

Table 2. WBC and lymphocyte subclasses in studied groups

\begin{tabular}{|c|c|c|c|}
\hline & Preterm neonates & Term neonates & Adults \\
\hline WBC $\left(\times 10^{3} / \mu \mathrm{L}\right)$ & $8.88 \pm 4.65$ & $13.68 \pm 7.59$ & $6.57 \pm 1.76$ \\
\hline Neutrophils $\left(\times 10^{3} / \mu \mathrm{L}\right)$ & $4.13 \pm 3.04$ & $7.89 \pm 5.49$ & $3.76 \pm 1.27$ \\
\hline Monocytes $\left(\times 10^{3} / \mu \mathrm{L}\right)$ & $1.32[0.84,1.63]$ & $1.88[1.06,2.31]$ & $1.00[0.00,1.00]$ \\
\hline Lymphocytes $\left(\times 10^{3} / \mu \mathrm{L}\right)$ & $3.32 \pm 1.37$ & $3.98 \pm 1.42$ & $2.03 \pm 0.61$ \\
\hline B $(\%)$ & $13.53 \pm 8.63$ & $10.73 \pm 4.73$ & $10.33 \pm 3.49$ \\
\hline NK (\%) & $6.92 \pm 3.93$ & $10.18 \pm 9.86$ & $14.26 \pm 7.86$ \\
\hline T $(\%)$ & $77.55 \pm 9.07$ & $77.69 \pm 12.8$ & $73.39 \pm 5.69$ \\
\hline Th $(\% \mathbf{T})$ & $73.88 \pm 9.01$ & $74.34 \pm 5.67$ & $58.35 \pm 9.93$ \\
\hline Tc $(\% \mathbf{T})$ & $23.29 \pm 9.30$ & $22.41 \pm 5.17$ & $33.65 \pm 8.22$ \\
\hline
\end{tabular}


The absolute lymphocyte counts were significantly different in preterm and term neonates when compared to adults $(p<0.001)$, the estimated mean value of the lymphocyte absolute count being greater in term neonates (Table 2). In both preterm and term neonatal populations, the absolute monocyte count was significantly higher than in healthy adults $(\mathrm{p}<0.001)$. When comparing the frequencies of $\mathrm{B}, \mathrm{NK}$ and $\mathrm{T}$ lymphocyte subclasses ( $\mathrm{T}$ cytotoxic $-\mathrm{Tc}$ and $\mathrm{Th}-\mathrm{T}$ helper), no differences were detected between the studied preterm, term neonates and adults except for a higher frequency of the NK lymphocyte subclass in preterm neonates when compared to adults $(p=0.001)$.

PBPS burst in adults. To establish the normative adult pattern of oxidative burst induced by opsonized E. coli and non-opsonized C. albicans, 26 healthy adults were used as controls during the study period. Data were corrected to the background activity of the same PBPs preparation incubated in the absence of any stimulus with saline. The adult neutrophils exposed to E. coli exhibited an approximately $60 \%$ increase in burst activity relative to control neutrophils $(p=0.004)$. The non-opsonized $C$. albicans yeast did not influence significantly the oxidative burst activity of the adult neutrophils when compared to the absence of stimulus $(p>0.05)$.

Monocyte burst activation in adults in the presence of opsonized $E$. coli was on average $44 \%$ higher than the activation of the saline control $(p=0.004)$, while the monocyte burst activation in adults in the presence of non-opsonized C. albicans was on average $1.98 \%$ greater than the activation of the saline control, but not statistically significant $(p=0.128)$.

PBPs burst in neonates versus adults. We found a significant difference in the percentage distribution of spontaneously activated granulocytes between term and preterm neonates compared to adults $(p<0.05)$. We also noticed that the median (interquartile range: [Q1, Q3]) percentages of spontaneously activated granulocytes were $9.44[2.63,20.88]$ for term neonates and $5.61[2.65,14.84]$ for preterm neonates versus $2.32[1.84,2.51]$ in adults. We observed greater point estimations of the median in preterm and term neonates than in the adult group (Table 3).

Table 3. Burst activation of granulocytes and monocytes triggered by exposure to various stimuli

\begin{tabular}{|c|c|c|c|c|c|c|}
\hline & \multicolumn{2}{|c|}{ Preterm neonates } & \multicolumn{2}{|c|}{ Term neonates } & \multicolumn{2}{|c|}{ Adults } \\
\hline & $\begin{array}{c}\text { Activated } \\
\text { granulocytes } \\
(\%)\end{array}$ & $\begin{array}{c}\text { Activated } \\
\text { monocytes } \\
(\%)\end{array}$ & $\begin{array}{c}\text { Activated } \\
\text { granulocytes } \\
(\%)\end{array}$ & $\begin{array}{c}\text { Activated } \\
\text { monocytes } \\
(\%)\end{array}$ & $\begin{array}{c}\text { Activated } \\
\text { granulocytes } \\
(\%)\end{array}$ & $\begin{array}{c}\text { Activated } \\
\text { monocytes } \\
(\%)\end{array}$ \\
\hline $\begin{array}{l}\text { Saline } \\
\text { solution }\end{array}$ & $\begin{array}{c}5.61 \\
(2.65-14.84)\end{array}$ & $\begin{array}{c}1.57 \\
(0.74-2.86)\end{array}$ & $\begin{array}{c}9.44 \\
(2.63-20.88)\end{array}$ & $\begin{array}{c}1.79 \\
(0.31-2.84)\end{array}$ & $\begin{array}{c}2.32 \\
(1.84-2.51)\end{array}$ & $\begin{array}{c}1.12 \\
(0.41-1.68)\end{array}$ \\
\hline fMLP & $\begin{array}{c}5.51 \\
(1.27-16.70)\end{array}$ & $\begin{array}{c}2.70 \\
(1.31-5.72)\end{array}$ & $\begin{array}{c}6.05 \\
(2.24-19.65)\end{array}$ & $\begin{array}{c}1.61 \\
(1.04-4.82)\end{array}$ & $\begin{array}{c}1.46 \\
(0.56-4.42\end{array}$ & $\begin{array}{c}0.41 \\
(-0.06-1.57)\end{array}$ \\
\hline PMA & $\begin{array}{c}86.33 \\
(75.63-93.46)\end{array}$ & $\begin{array}{c}64.77 \\
(36.22-91.65)\end{array}$ & $\begin{array}{c}81.62 \\
(72.76-94.13)\end{array}$ & $\begin{array}{c}66.89 \\
(22.76-95.15)\end{array}$ & $\begin{array}{c}91.49 \\
(81.42-96.90)\end{array}$ & $\begin{array}{c}49.25 \\
(29.37-76.30)\end{array}$ \\
\hline E. coli & $41.19 \pm 20.63$ & $38.97 \pm 20.73$ & $50.01 \pm 26.50$ & $39.85 \pm 24.36$ & $58.32 \pm 33.46$ & $46.82 \pm 21.05$ \\
\hline C. albicans & $\begin{array}{c}3.02 \\
(1.87-4.53)\end{array}$ & $\begin{array}{c}2.34 \\
(1.11-3.27)\end{array}$ & $\begin{array}{c}4.35 \\
(1.69-12.69)\end{array}$ & $\begin{array}{c}2.11 \\
(0.51-6.45)\end{array}$ & $\begin{array}{c}2.03 \\
(1.31-3.51)\end{array}$ & $\begin{array}{c}1.44 \\
(0.62-3.76)\end{array}$ \\
\hline
\end{tabular}

A difference with a tendency towards statistical significance was identified between the granulocyte activation triggered by $E$. coli in premature neonates and the control adults $(41.19 \pm 20.63 \%$ vs. $58.32 \pm 33.46 \%, p=0.058)$. Although the degree of granulocyte activation was lower in the premature neonates when stimulated with the $E$. coli suspension than in term neonates, in our study it did not reach a statistically significant difference $(41.19 \pm 20.63 \%$ vs. $50.01 \pm 26.50 \%, p=0.472$ ).

We found no behavioral differences in the preterm and term granulocytes exposed to the physiological fMLP stimulus when compared to the adult granulocytes. We did notice a higher degree of PMN activation in the presence of the physiological fMLP stimulus in preterm and term neonates than in the adult granulocytes $(5.51[1.27,16.70]$ preterm vs. $6.05[2.24,19.65]$ term vs. $1.46[0.56,4.42]$ adults), although not statistically significant $(p>0.05)$.

There was no difference in PMN activation triggered by the chemotactic peptide PMA in preterm and term neonates when compared to adult granulocytes $(p>0.05)$. The chemotactic peptide PMA generated in the granulocytes of all the studied groups a similar maximal degree of activation: 86.33 [75.63, 93.46] preterm vs. 81.62 [72.76, $94.13]$ term vs. 91.49 [81.42, 96.90] adults.

When examining the effect the non-opsonized C. albicans yeast incubation had on the granulocyte activation, we identified no difference in preterm and term samples when compared to adults $(p>0.05)$. The unopsonized $C$. albicans stimulus caused a low granulocyte activation in all three studied groups regardless of their degree of maturation $(3.02[1.87,4.53]$ in preterm vs. 4.35 [1.69, 12.69] in term vs. 2.03 [1.31, 3.51] in adults). Although the low granulocyte activation degree was similar, it reached a statistically significant difference between the term neonates and the adult study group $(p=0.034)$ (see Figure 1). 


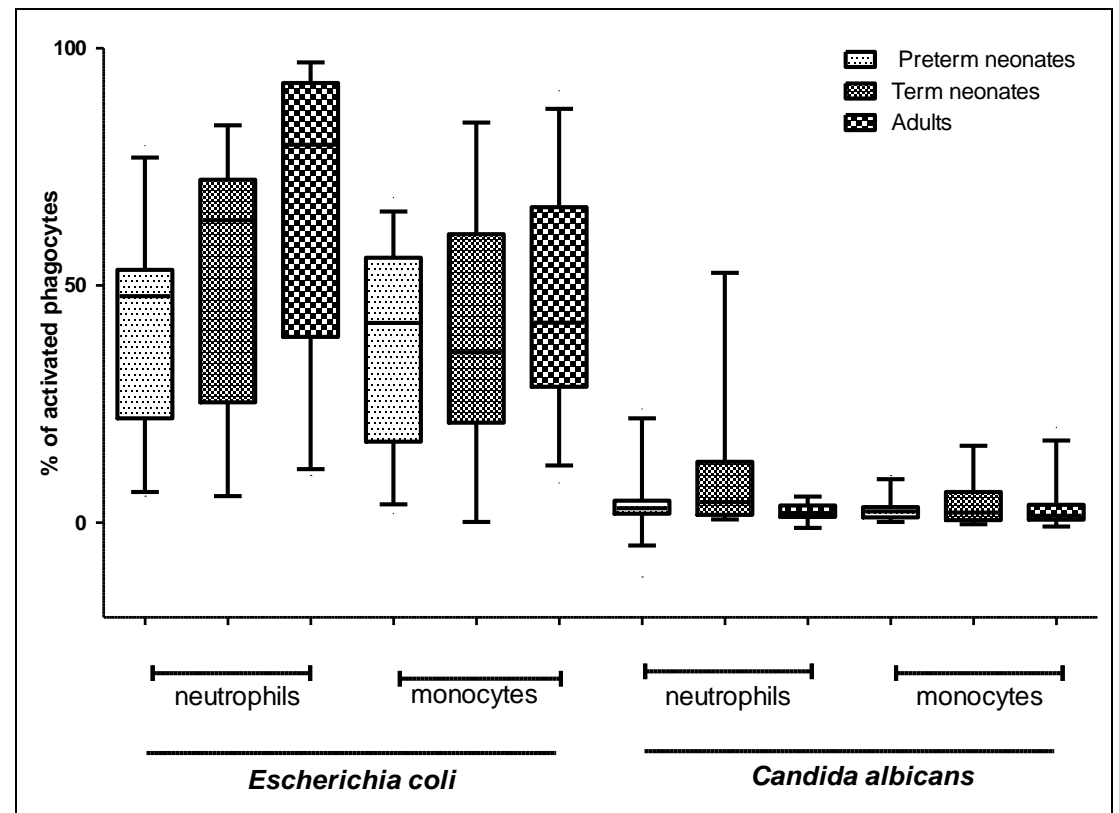

Figure 1. Neutrophil and monocyte activation triggered by E. coli and C. albicans. The box-plots contain medians and minimum-maximum values of activated PBPs

Examining the spontaneous activation of the monocyte population in the presence of the saline solution, we detected no statistical significance among the premature neonates vs. term and premature vs. adults (adjusted $\mathrm{p}>0.05$ ). The median [Q1, Q3] percentages were 1.57 [0.74, $2.86]$ in preterm and $1.79[0.31,2.84]$ term vs. 1.12 [0.41, $1.68]$ in adults.

We identified a mean difference with a tendency towards statistical significance between the percentage of monocytes activated by exposure to $E$. coli in premature neonates compared to the control adults $(38.97 \pm 20.73 \%$ vs. $46.82 \pm 21.05 \%, p>0.05)$. Although the degree of monocyte activation was lower in the premature neonates when stimulated with the opsonized $E$. coli than in the term neonates, in our study it did not reach a statistically significant difference $(38.97 \pm 20.73 \%$ vs. $39.85 \pm 24.36 \%, p>0.05)$.

\section{Discussions}

Many facets of the neonatal immune deficiency contribute to sepsis and other infectious syndromes in the newborn. Because of the important role the production of ROS by PBPs has in defense, we chose to focus on this mechanism.

In our study, although the preterm neonates showed a lower capacity to up-regulate the ability of the neutrophil to generate ROS than the term neonates when exposed to the $E$. coli stimulus, the difference in neutrophil recruitment had a tendency towards statistical significance only when compared to the healthy adults. We believe that this difference in activation could become significant if we could have accessed larger study groups. Although the unlabeled $E$. coli stimulus provided by the commercial kit was opsonized in order to facilitate rapid granulocyte activation, our results show that the percentage of oxidative active neutrophils in preterm neonates remains low even when using whole blood which contains neonatal humoral factors such as complement and immunoglobulins.

Our results are consistent with the ones described by similar studies that focused on other living microbes such as coagulase-negative Staphylococci and Streptococcus epidermidis. BJÖRKQVIST \& al described a lower percentage of oxidative active neutrophils after bacterial stimulation in preterm compared with term newborns, but the difference they found was not statistically significant. When they compared the mean fluorescent intensity in the preterm and term neonates, it was statistically significant in favor of the term neonates for all studied bacterial strains (BJÖRKQVIST, 2004).

Candida albicans infections are life-threatening conditions and a common cause of late-onset sepsis in premature neonates. They are associated with significant morbidity, morality, health related expense and neurodevelopmental impairment (DESTIN, 2009). According to the published data, invasive Candida infections affect immunosuppressed patients and those with defects of the immune system.

Previous studies performed on preterm and term neonates have focused mainly on the quantification of the oxidative burst activity of PMN by using bacteria as particulate stimulus. Because bloodstream infections due to Candida species are a major cause of morbidity and mortality in neonates and children, nosocomial candidemias ranging from $10 \%-20 \%$, we have decided to study one of the first steps of the non-specific cellular immune response that consists in PBPs activation and production of ROS when stimulated with living Candida albicans yeast cells. Our results have shown a very low activation of PBPs and consecutive low production of ROS both in adults and 
neonates when live $C$. albicans yeast cells were used as particulate stimulus. In some cases, burst activation in the presence of living $C$. albicans was even lower than the spontaneous activation of PBPs verified by the saline solution tube, thus indicating an inhibitory effect of the yeast cells upon the production of ROS. In our study, this low activation of PMN and monocytes was similar in all three studied groups with no detected statistically difference.

In our data set, the analysis of the lymphocyte subclasses has revealed a slightly higher but not significant difference in the frequency of $\mathrm{CD} 19^{+} \mathrm{B}$ lymphocytes as well as a significantly higher frequency of $\mathrm{CD}^{+}{ }^{+} \mathrm{T}$ lymphocytes (Th) in healthy preterm and term neonates when compared to adults. Our results are concordant with data provided by previous studies on the phenotypic differences in leucocyte populations among healthy preterm and full-term neonates (QUINELLO, 2014). We identified a significantly lower percentage of $\mathrm{CD}^{+} \mathrm{T}$ lymphocytes (Tc) in both preterm and term neonates than in adults (see Table 2).

Some studies have shown that there are additional variables that could impact ROS production. The study conducted by WELLINGTON \& al. showed that live C. albicans suppresses primary the phagocyte production of ROS inspite of the proven stimulatory effects of the fungal surface structures (1,3- $\beta$-glucan and 1,4- $\beta$-glucan) upon ROS production through the activation of dectin-1 (RUBIN-BEJERANO, 2007; P. BONFIM-MENDONÇA, 2014). The study also showed that live C. albicans scavenged more ROS than heat killed $C$. albicans. Nevertheless, due to the fact that live and heat killed Sacharomyces cerevisiae scavenging was similar to that observed in $C$. albicans, they concluded that scavenging alone cannot account for the observed suppression of ROS production (WELLINGTON, 2009).

Other studies, such as the one published by FROHNER \& al. have concluded that ROS induction is independent of morphology as both yeast and hyphal forms of $C$. albicans trigger ROS in primary innate immune cells such as macrophages and dendritic cells (FROHNER, 2009). Nevertheless, studies have shown that C. albicans cell surface superoxide dismutase encoded by the Sod5 gene degrades extracellular ROS produced by immune cells, thus overriding the glucan burst activation (FROHNER, 2009). Neutrophils seem to induce also Sod5 expression, although they inhibit the yeast-to-hyphal formation in C. albicans (MIRAMÓN, 2013). These assertions are consistent with our research that describes a low ROS production and even burst inhibition in some cases in PMN and monocytes when $C$. albicans was used as particulate stimulus.

Our results are also consistent with other studies such as the one of YOST \& al which has shown the importance of NETs (neutrophil extracellular traps) formation by PMN in order to induce an adequate non-specific cellular immune response. These DNA complexes which are thought to form via a unique death pathway signaled by nicotine adenine dinucleotide phosphate (NADPH) oxidase-generated ROS, accomplish both capture and killing of bacteria and fungi, which are antimicrobial activities that can be suppressed by endonucleases and DNases expressed by some organisms. The study has also revealed that term neonatal PMN failed to produce NETs when incubated with live E. coli, Staphylococcus aureus and PMA in contrast to adult neutrophils. This phenomenon was associated with impaired bacterial killing and thus it could contribute to the pathogenesis of severe infections in early life (YOST, 2009). Also, ROS production did not complement the defect in NET formation by neonatal neutrophils as it happened in adult cells with inactivated NADPH oxidase, proving that ROS are necessary, but not sufficient signaling intermediaries. Thus, the defective ROS production that we have identified in the studied neonatal groups seems to be accompanied also by insufficient bacterial killing due to a low NETs production in neonates. Also, others studies have shown that while the killing of opsonized $C$. albicans is dependent upon production of ROS by the NADPS oxidase system, the killing of unopsonized $C$. albicans, as in our case, is dependent solely on the complement receptor 3 (CR3) and the signaling proteins phosphatidylinositol-3-kinase and caspase recruitment domanin-containing protein 9 (CARD9) (GAZENDAM, 2014).

Commercial methods such as the one used in our study (Phagoburst ${ }^{T M}$, Glicotope) allow exact quantification of granulocyte and monocyte ROS production by fluorometric analysis using whole blood, thus making the method more approachable. The assay that uses dihydrorhodamine 123 as a flourogenic substrate has already been validated and its efficiency in correctly distinguishing patients suffering from granulocyte defects has been verified by previous studies (LUNN, 2000), providing results within a short period of time, usually within a few hours. Considering the severity and the rising frequency of fungal systemic infections among neonates, inspite of adequate diagnosis and treatment, we have considered completing the commercial kit we used with $C$. albicans as an extra fungal stimulus. Our results may not be very relevant because of the complete lack of opsonins used in the study, WELLINGTON \& al. having clearly proven that phagocytosis, and by this we assume that bust oxidation also, is clearly enhanced in the presence of these molecules (WELLINGTON, 2009).

Limitations of the study. The limitation of our study consists in the relatively small samples of patients that we could assess, as well as the rather variable number of cells that could be analyzed per subject due to the variable number of $\mathrm{WBC}$ of the recruited neonates.

\section{Conclusions}

The present study showed a deficit in ROS production of the premature neonate granulocyte when exposed to opsonized E. coli. A similar behavior could not be identified in preterm or term PBPs compared to adult PBPs when non-opsonized $C$. albicans was used as a stimulus. The immaturity of the preterm granulocytes and monocytes did not distinguish greatly their almost absent response to fungal stimuli from the low activation of adult PBPs. 


\section{Acknowlegements}

This study was supported by the Research Grants of the University of Medicine and Pharmacy of Târgu Mureș, Romania, Project number 15/23.12.2014. The authors thank the medical doctors and nurses of the Regional Center of Neonatal Intensive Care Unit UGON and Neonatology Department of Tîrgu Mureș for the help provided with the selection of adequate study candidates and blood collection. We thank also Anca Bacârea, M.D., for the evaluation of blood smears and the laboratory technicians that helped with the experiments.

\section{Disclosure}

The authors declare no conflicts of interest.

\section{References}

1. BENJAMIN DK, STOLL BJ, FANAROFF AA, MCDONALD SA, OH W, HIGGINS RD, et al. Neonatal candidiasis among extremely low birth weight infants: risk factors, mortality rates, and neurodevelopmental outcomes at 18 to 22 months. Pediatrics 2006 Jan, 117(1):84-92. DOI:10.1542/ peds.2004-2292

2. BJÖRKQVIST M, JURSTRAND M, BODIN L, FREDLUND H, SCHOLLIN J. Defective Neutrophil Oxidative Burst in Preterm Newborns on Exposure to Coagulase-Negative Staphylococci. Pediatr Res 2004 Jun, 55(6):966-71. DOI:10.1203/01.pdr.0000127018. 44938.89

3. BONFIM-MENDONÇA P DE S, RATTI BA, GODOY J DA SR, NEGRI M, LIMA NCA DE, FIORINI A, et al. $\beta$-Glucan induces reactive oxygen species production in human neutrophils to improve the killing of Candida albicans and Candida glabrata isolates from vulvovaginal candidiasis. PLoS One 2014,9(9):e107805. DOI:10.1371/journal.pone.0107805

4. CHIESA C, PANERO A, OSBORN JF, SIMONETTI AF, PACIFICO L, OSBORN JF, et al. Diagnosis of neonatal sepsis: a clinical and laboratory challenge. Clin Chem 2004 Feb 1, 50(2):279-87. DOI:10.1373/ clinchem.2003.025171

5. CHIRICO G, LODA C. Laboratory aid to the diagnosis and therapy of infection in the neonate. Pediatric reports 2011, 3(Table 1):1-5.

6. DESTIN KG, LINDEN JR, LAFORCE-NESBITT SS, BLISS JM. Oxidative burst and phagocytosis of neonatal neutrophils confronting Candida albicans and Candida parapsilosis. Early Hum Dev 2009 Aug, 85(8):531-5. DOI:10.1016/j.earlhumdev.2009.05.011

7. FRADIN C, DE GROOT P, MACCALLUM D, SCHALLER M, KLIS F, ODDS FC, et al. Granulocytes govern the transcriptional response, morphology and proliferation of Candida albicans in human blood. Mol Microbiol 2005 Feb 18, 56(2):397415. DOI:10.1111/j.1365-2958.2005.04557.x
8. FROHNER IE, BOURGEOIS C, YATSYK K, MAJER O, KUCHLER K. Candida albicans cell surface superoxide dismutases degrade host-derived reactive oxygen species to escape innate immune surveillance. Mol Microbiol 2009, 71(1):240-52. DOI:10.1111/j.1365-2958.2008.06528.x

9. GAZENDAM RP, HAMME JL VAN, TOOL ATJ, HOUDT M VAN, VERKUIJLEN PJJH, HERBST M, et al. Two independent killing mechanisms of Candida albicans by human neutrophils : evidence from innate immunity defects. Blood 2014, 124(4):590-8. DOI: 10.1182/blood-2014-01-551473

10. GRUMACH AS, CECCON ME, RUTZ R, FERTIG A, KIRSCHFINK M. Complement profile in neonates of different gestational ages. Scand J Immunol 2014, 79(4):276-81. DOI:10.1111/sji.12154

11. KÄLLMAN J, SCHOLLIN J, SCHALÈN C, ERLANDSSON A, KIHLSTRÖM E. Impaired phagocytosis and opsonisation towards group B streptococci in preterm neonates. Arch Dis Child Fetal Neonatal Ed 1998 Jan, 78(1):F46-50. DOI:10.1136/fn.78.1.f46

12. LUN A, SCHMITT M, RENZ H. Phagocytosis and oxidative burst: Reference values for flow cytometric assays independent of age. Clin Chem 2000, 46(11): 1836-9.

13. MIRAMÓN P, KASPER L, HUBE B. Thriving within the host: Candida spp. interactions with phagocytic cells. Med Microbiol Immunol 2013 Jun 25, 202(3): 183-95. DOI:10.1007/s00430-013-0288-z

14. QUINELLO C, SILVEIRA-LESSA AL, CECCON MEJR, CIANCIARULLO MA, CARNEIRO-SAMPAIO M, PALMEIRA P. Phenotypic differences in leucocyte populations among healthy preterm and full-term newborns. Scand J Immunol 2014, 80(1):57-70. DOI:10.1111/sji.12183

15. RUBIN-BEJERANO I, ABEIJON C, MAGNELLI P, GRISAFI P, FINK GR. Phagocytosis by human neutrophils is stimulated by a unique fungal cell wall component. Cell Host Microbe 2007 Jul 12, 2(1):55-67. DOI:10.1016/j.chom.2007.06.002

16. SCHELONKA RL, INFANTE AJ. Neonatal immunology. Semin Perinatol 1998 Feb, 22(1):2-14. DOI:10.1016/ s0146-0005(98)80003-7

17. WELLINGTON M, BLISS JM, HAIDARIS CG. Enhanced phagocytosis of Candida species mediated by opsonization with a recombinant human antibody single-chain variable fragment. Infect Immun 2003 Dec, 71(12):7228-31. DOI:10.1128/iai.71.12.7228-7231.2003

18. WELLINGTON M, DOLAN K, KRYSAN DJ. Live Candida albicans suppresses production of reactive oxygen species in phagocytes. Infect Immun 2009 Jan, 77(1):405-13. DOI:10.1128/IAI.00860-08

19. YOST CC, CODY MJ, HARRIS ES, THORNTON NL, MCINTURFF AM, MARTINEZ ML, et al. Impaired neutrophil extracellular trap (NET) formation: a novel innate immune deficiency of human neonates. Blood 2009 Jun 18, 113(25):6419-27. DOI:10.1182/ blood-2008-07-171629 